\title{
Gilles, R. (2017). Histoire des droites en France de 1815 à nos jours. Paris, Francia: Perrin, 634 pp.
}

Marcela Ferrari ${ }^{1}$

El estudio de las derechas convoca a historiadores de todo el mundo en un presente en el que aquellas no dejan de crecer ¿Cómo surgieron, se transformaron, se escindieron o se multiplicaron? ¿Qué actores las encarnaron? ¿Qué formas de organización se dieron? ¿De qué modo impactaron sobre ellas los grandes desafíos nacionales e internacionales? ¿Cuál fue su relación con el Estado? Estas son solo algunas de las preguntas que movilizan a los investigadores abocados a ese objeto disciplinar.

La actualidad del problema señala la pertinencia de reseñar esta obra de Gilles Richard, historiador francés especializado en historia política, director de la Maestría en Historia de la Universidad Rennes 2, quien sintetiza la historia de las derechas en Francia durante los últimos dos siglos o, mejor aún, recorre la historia de Francia en el largo plazo utilizando como puerta de entrada el estudio de las derechas. Este trabajo de síntesis, de exquisita escritura, se remonta a los comienzos del siglo XIX y llega hasta nuestros días. El autor pone de manifiesto un debate necesario y vacante en la historiografía francesa, en diálogo con quien fuera su maestro y director de tesis de Estado, René Rémond, a quien dedica el libro.
Rémond había dejado prácticamente clausurado el tratamiento sobre las derechas (legitimista, orleanista y bonapartista) y su evolución (tradicionalistas, liberales, gaullistas). Richard, nutrido de nuevas preguntas que ponen en evidencia tanto una nueva relación pasado/presente como los avances de la disciplina, cuestiona aquella visión uniformizante y evolutiva, la desnaturaliza e invita a la reflexión. En su investigación, descubre los desafíos enfrentados por esas nebulosas de derechas, que habitan familias políticas, una categoría analítica que identifica como grandes corrientes o fuerzas políticas, difíciles de definir más que en su pluralidad, y que actúan dentro de un sistema de relaciones binarias marcado por el clivaje izquierdas-derechas.

Para Richard las derechas francesas, irreductibles a la unidad, están sometidas a reconfiguraciones permanentes. Sus protagonistas son actores que circulan entre diversos grupos internos que, en momentos clave, son disparados por las sucesivas coyunturas y, en los menos tumultuosos, pueden mantener sus pretensiones o no, lo que suele conllevar a salidas no siempre honrosas de los propios grupos, ligas, fracciones o partidos de pertenencia. Divisiones, realineamientos, enfrentamientos, emer-

\footnotetext{
${ }^{1}$ Universidad Nacional de Mar del Plata. Consejo Nacional de Investigaciones Científicas y Técnicas. Contacto: marcelapatriciaferrari@gmail.com
} 
gencia de nuevas corrientes y recomposiciones sobre otras preexistentes, aparecen una y otra vez en un relato que concibe la metamorfosis de esos grupos en relación con el resto de los actores políticos, los gobiernos del Estado $\mathrm{y}$ las coyunturas internacionales.

A diferencia de otros autores que analizan la sociabilidad y la cultura política de las derechas, los protagonistas de este texto son los actores colectivos, los partidos políticos. Richard se aparta de otras obras más cercanas a la sociabilidad y la cultura política de derechas, para volverse hacia los avatares de las organizaciones aun cuando por momentos se desdibujen en múltiples reconfiguraciones. Dentro del conjunto de actores también cobran relevancia los dirigentes políticos, a quienes el autor observa en su desempeño político y a partir de trayectorias individuales. Es en las decisiones de estos últimos donde se perciben con gran nitidez los meandros de carreras cambiantes, de decisiones que inciden en cuestiones colectivas, de tendencias al agrupamiento, al fraccionamiento y aun a la disolución.

Es que la dinámica siempre cambiante de las derechas es un eje en torno al cual pivotea el relato. Ser de derechas, afirma el autor, no es un estado que se defina de una vez y para siempre; y esto es tan válido para las organizaciones políticas como para las vidas de los hombres de derechas. A lo largo de dos siglos, por cierto, los clivajes y los nudos que desafiaron las opciones, los discursos y las prácticas de las derechas, cambiaron tanto como se transformó el hecho de experimentar la adscripción a alguna versión de esa gran familia de opinión y acción. Los hombres de derechas fueron desafiados en el siglo XIX por la República democrática y laica, sufrieron derrotas. Pero en los años veinte sus ideas solían ser sinónimo de modernidad. A la salida de la segunda guerra mundial los grupos de derechas se multiplicaron y algunos de ellos llegaron al poder de la mano de De Gaulle, momento en el que experimentaron sus mayores crecimientos. Luego, vivieron con vergüenza los treinta gloriosos, que finalizaron con el ascenso de la derecha liberal al gobierno. Después de los años ochenta y, aún más, ante la amenaza de extinción de las izquierdas de comienzos del siglo XXI, el repunte de las derechas cobró vigor, transformadas por liberales y nacionalistas, mundialistas y patriotas. La identificación de esa dinámica permanente y la síntesis del conjunto de respuestas ofrecidas por las distintas derechas en diferentes momentos de los dos siglos recorridos, constituyen grandes aciertos de este relato.

La obra se organiza en una introducción, cuatro partes -que reúnen un total de veinte capítulos- y una conclusión. En la introducción se definen con claridad los ejes ya aludidos que articulan el relato: el tiempo largo, la multiplicidad de las derechas, las familias políticas, los partidos. La primera parte (1815-1914) analiza los desafíos de las derechas que, de encontrarse en el poder en las versiones identificadas por Rémond, en 1870 son derrotadas por los republicanos y se ven forzadas a una mutación, de la que no está exento el campo católico. Aun en tiempos del affaire Dreyfus y en vísperas de la Gran Guerra, las derechas continúan siendo 
minoritarias en Francia.

La segunda parte recorre el período de entreguerras. El análisis enfoca temas tales como la llegada de las derechas al poder en los tempranos años veinte, la emergencia de la democracia cristiana y el agrarismo, el imperativo de nacionalización de las masas, la radicalización de las derechas y el crecimiento de las ligas nacionalistas. Las derechas, desafiadas $-\mathrm{y}$ derrotadas- por el Frente Popular, recuperan el poder en 1938 cuando se enfrentan ante una nueva encrucijada: la toma de posición ante la Guerra, el nazismo y, en 1944, hasta cierta unión con las izquierdas en aras de la liberación nacional.

La tercera parte analiza los «Treinta Gloriosos». La emergencia del gaullismo, desprendido de un movimiento liderado por los democristianos, y la obsesión frente a la «amenaza comunista», que parece alterarlo todo, dan el tono político a los inicios de este período caracterizado por la expansión económica, el ascenso de las izquierdas, la aparición de un nuevo frente popular liderado por los comunistas y, con posterioridad, la irrupción del Mayo francés. En ese contexto, cuando eran cuestionadas y aun reducidas a un lugar vergonzante, las derechas sostenían una competencia interna que enfrentaba a gaullistas y liberales. El período concluye con beneficio de inventario para los segundos con la llegada al poder de Va- léry Giscard d'Estaing, un moderado, que abre la hegemonía de ese sector que aún continúa en el poder.

La cuarta y última parte analiza la profundización de la escisión de nacionalistas y liberales a partir de 1974 hasta hoy, mientras las izquierdas se desgranan y se desdibujan en un mundo profundamente cambiado con la desaparición de la Unión Soviética y la emergencia de China. A esto se agrega, notablemente, el desafío de la integración de Francia a la Unión Europea como horizonte de largo plazo, con el triunfo del neoliberalismo y una izquierda que contradice sus mismos principios.

En suma, las derechas han cambiado. El gaullismo está muerto y enterrado, el nacionalismo juega sus apuestas más fuertes frente a la mundialización con el sorprendente apoyo de un electorado joven y ante una izquierda en migajas. La hegemonía de derechas, hoy, parece indiscutible. Sin embargo, según mostró Gilles Richard, siempre puede haber recomposiciones políticas. Si ser de derechas no es un atributo ni determina un único comportamiento en sociedad, queda abierta la posibilidad de evoluciones y transformaciones. Ese parece ser el legado de este libro que entiende a las familias de derechas en relación con la configuración política, nacional e internacional, en que se desenvuelven. 